\section{THE DEVELOPMENT AND TRENDS OF LITERARY STUDIES IN THAILAND ${ }^{1}$}

\author{
Trisilpa Boonkhachorn ${ }^{2}$
}

\section{Introduction}

The purpose of this article is to survey the development and trends in literary studies in Thailand from their beginnings to the present with particular focus on the three decades between 1965-1995. Analysis is carried out on a selection of distinguished literary research studies which have not only stimulated scholarly debate but also influenced new study trends, paradigms or reinterpretations of major literary texts. From this analysis an attempt will be made to criticize and evaluate these research studies and to suggest what could be the future trends in Thai literary studies.

The contents is divided into 5 parts.

Prologue: Paradigm Shift in Thai Literary Studies

Part 1: The Pragmatist: Traditional Thai Poetics As a Paradigm for Literary Studies

Part 2: The Hegemony: Literature as National History and Identity

1 This article is the conclusion to my two previous research articles : The Development and Trends of Literary Studies in Thailand from the Beginning to 1985 (Boonkhachorn: 1987) and The Development of Literary Studies in These Past Three Decades and Trends For the Future (in progress).

2 Assistant Professor, Department of Comparative Literature, Faculty of Arts, Chulalongkorn University, Bangkok, Thailand
Part 3: The West Wind: The Paradigm of The New Criticism

Part 4: The Anti-Hegemony: The Local Voice

Part 5: The Outsiders: The Extrinsic and the Interdisciplinary Paradigms

Trends for the Future: The Interdisciplinary Paradigms

\section{Prologue: Paradigm Shift in Thai Literary Studies}

Thomas S. Kuhn in The Structure of Scientific Revolutions (1970; first published 1962) suggested that particular learned communities or specialities rested upon the acceptance of "a set of recurrent and quasi-standard illustrations of various theories in their conceptual, observational, and instrumental applications" These are the community's paradigms, which can be found revealed in its "textbooks, lectures, and laboratory exercises. (Kuhn: 1970, 43) A paradigm is constituted by a set of beliefs which both enables and constrains research: a framework or scaffold which can underpin or support further work but which of necessity also excludes a range of possibilities. Kuhn's concept of the paradigm shift enters into literary study in relation, very often, to arguments about interpretation. We interpret the evidence of a text differently when our literary paradigms change, just as the scientist interprets the evidence provided by an 
experiment when his or her scientific paradigms change. (Hawthorn: 1992)

In this article, an effort will be made to analyse the paradigms and the paradigm shifts in Thai literary studies from their beginnings to the present .

\section{Part 1: The Pragmatist: Traditional Thai Poetics as a Paradigm for Literary Studies}

Before contact with the West, the centres of cultural and literary activities were the royal palace and the temples. The literary texts which have been handed down to the present time were products of these two centres. Popular, common or folk literature certainly did exist but, its literary periods are hard to trace. Literature supported by royalty had authority over all other literary activities, up until the influence of the Western education system on Thai literary studies took effect.

The word "poetics" is Greek in origin and means "the art of poetic creation" Poetics signifies writing that deals with the art of poetry or presents a theory of the art. The most famous instance of such a treatise is Aristotle's Poetics. Emil Staiger, in his afterword in Basic Concepts of Poetics, concludes that poetics is only a question of the practical instructions which will accomplish for the poet what the doctrine of counterpoint and harmony does for the composer. Poetics teaches what it is that constitutes the nature of poetic creation. Poetics organizes the available models and in so doing poses the problem of genre. Poetics instructs the experienced poet wanting to write.

Poetics in this sense is similar to the concept of poetics which appears in the ancient Thai textbooks written about prosody. Even though, in those ancient times, there was not a Thai word for "poetics" (it having only been coined a few decades ago; the result of the influence of Western literary criticism on Thai literary studies) a concept of Thai poetics existed and emphasised pragmatism or practical knowledge over theoretical knowledge. In Thai, there is nothing which corresponds to the Poetics of Aristotle. Though Indian textbooks about prosody such as Wuttothai and Alangkarasat, (the art of poetics and elaboration) were cited, they were not actually translated into Thai until the beginning of the Rattanakosin era. Kusuma Raksamani in her research titled "Kan Wikhro Wannakhadi Thai Tam Thritsadi Wannakhadi Sanskrit" (The Analytical Study of Thai Literature by Sanskrit Theory of Literature) concludes that the Sanskrit theory of literature (found in Alangkarasat) did not have influence on the sphere of Thai literature until the Rattanakosin era. (Raksamani: 1989). Thai scholars appear to have selected and adapted only certain parts of these Pali and Sanskrit textbooks, to which they added Thai examples and commentaries based on their own aesthetic and moral values. Even though there is no elucidation of the concept of Thai poetics, this concept can be indirectly derived from literary texts themselves and from textbooks about prosody.

The concept of poetics thus existed in Thai literary history before contact with the West, and before a word for it was actually coined in Thai. Some excerpts from traditional poetry express the poetic repertoire, the poetic process and the aesthetic values of poetry and this indicates that from the very beginnings of Thai literary history, the poetic phenomenon was closely observed by at 
least the poets themselves. Thai poetics puts heavy emphasis on the musicality of words. This musicality has its origins in the tonal aspect of the Thai language itself, from the choice of words (influenced by prosodic constraints, rhyme, alliteration and assonance), and from the special techniques required by each prosodic form.

When explaining poetic creation or its aesthetic values, traditional Thai poetics tends to focus on the musicality of words. The aesthetic value of poetry rests heavily on the quality of its melody, this being created by the beauty of the sounds used. This melody of sounds refers to their smoothness to the ear, which originates from a harmonious choice of words arranged in a well organised order, dictated by poetic constraints and the specified techniques of expression.

Emphasis on the musicality of words was obvious from the beginning of the emergence of Thai poetry, during the early Ayutthaya period (1350-1488). Three masterpieces of this period, Lilit Yuan Phai, Thawathosamat and Lilit Phra Law, express a similar standard of poetic evaluation. During that time there existed a poetic convention refered to as "attawiphak" or self-evaluation, by which poets (or scribes) evaluated their own works; they likened their melodious poetry to celestial garlands which adorned the ears of its listeners. According to poets their excellent poetry would endure throughout time. The confidence with which the poets promoted their own works is apparent and attributable to the fact that, because their works were patronised by royalty, the poetry which they devoted and dedicated to the monarch and presented in praise of him and for his entertainment, could only be perfect.

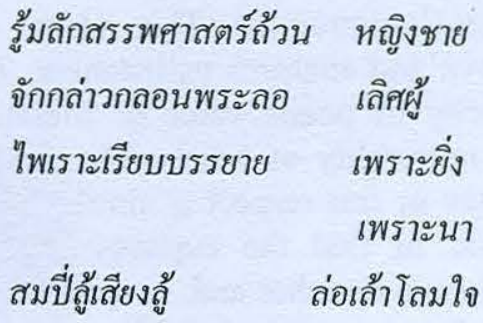

Having known all knowledge of women and men,

I will tell the poetic story of

Phra Law, the Perfect,

Narrated melifluously, most enchantingly,

Together with the sound of a melodious alluring flute.

In another stanza from the same source, Lilit Phra law expresses the poet's evaluation of his own poetry along with an expression of his intention to please his royal patron.

สรวลเสียงขับอ่านอ้าง ใดปาน
ฟังเสนาะใดปูน เปรียบได้
เกลากลอนกล่าวกลกานท์
ถวายบำเรอท้าวไท้ กิรลอม ใจนา

The chanting pleasant sounds are beyond compare,

Peerless, melodious,

The artistic poetry soothes the hearts, It is provides for the meritorious king.

It is obvious that the aesthetic value of this work is based on the melodious sounds created by a meticulously arranged narrative, comparable to the sound of a 
musical instrument. This verbal melody moves and enchants its listeners. The first priority of poetic value or literariness is the musicality of words. The function of poetry in this respect is similar to that of music in that the euphony of rhythms enchants, enriches and, in some instances, enlightens its listeners. This emphasis on the quality of sounds is still evident in the poetry of the modern period, though it is not the sole quality by which it is evaluated.

Another interesting observation can be made from these excerpts. The poetic repertoire expressed here consists of three elements; the producer (the narrator or chanter), the text (not the written one but that which is performed accompanied by music) and the receiver (who is emotionally moved by what is heard). As for the narrator or poet, he claims to have knowledge and understanding of all men and women, in effect human nature. $\mathrm{He}$ is therefore perfect (by his own estimation), to narrate this poem which concerns human passions. From a Buddhist point of view, passionate love is a source of trouble and misery. An experience and mature understanding of human nature and emotions are the basic knowledge a poet is supposed to have in order to compose artistic poetry. They are therefore part of poetic creation.

The aesthetics of Thai poetry rests solidly upon the quality "phairo", which signifies that which is "melodious, sweet, musical and harmonious, pleasing to the ears and tuneful."

The boundaries of poetry and music are interrelated in the area of aesthetics. The poetic process can be divided into three major elements: the poetic process, the medium and the receiver. The creative process includes the melodious quality of sounds, the action of the creative process and the action of the sender. The medium consists of words and sounds. The receiver process the action of receiver and the effect on the receiver. In the receiver process, the only action mentioned is listening and the effect on the listeners which can be divided into three steps. First, poetry like music, addresses itself to the ears. Secondly, it entertains, moves, enchants or soothes the heart and the soul of the listeners. In some cases it will reach the third stage; that is, it will broaden the mind of learned persons or scholars. Poetry can entertain, enchant and enrich the ears, the heart and the mind of those who listen to it.

Thomas Hudak in his chapter about "The Aesthetic of Sound" in The Indigenization of Pali Meters in Thai Poetry notices that the central problem of the definition of what constitutes a melodious sound (phairo') is left to the student's intuition. Hudak, from the linguistic point of view, concludes that the specific techniques used to create a language that is melodious are reduplication, intensification, the use of puns, the use of elaborate expressions, the use of particles, and the use of special vocabulary. (Hudak: 1990)

What Hudak explains as the "student's intuition" or "subjective" can be perceived from the Thai point of view as "learning from the Masters" or "listening to the voices of authority." This traditional way of learning, in the Thai social context, means that competence in reading poetry and aesthetic evaluation, are based on a student's knowledge of prior texts. The more one reads, the more one can develop the ability to evaluate because the familiarity of the poetic sounds of prior texts will become the norms of poetic 
evaluation. In other words, memory becomes the basis of aesthetic evaluation. This way of learning is common in every field of traditional Thai arts. For example, the way to learn a Thai musical instrument tends to be by heart rather than by musical notes. The "wai khru" tradition or "pay respect to the teachers or masters" tradition is, therefore, very significant in the Thai social context because the knowledge from the teacher will guide the student's way to experience and to encourage his or her own creativity.

The authoritative reference or the voice of the master has been used as a paradigm of learning since Jindamani, the first textbook that explains the "science" of poetry by concentrating on prosodic form. In Jindamani, each prosodic form is explained briefly in prose and is followed by the pattern of numbers of words with rhymes and tonal constraints. The best example of that prosodic form, an excerpt from a literary text, is given as the masterpiece of that genre. Then the constraints of that prosodic form are explained in that prosodic form itself. This pragmatic way of learning has the immediate effect of incorporating the aesthetic values in the unity of the sounds and meaning. It is understood that the accumulation of the authorities in memory enables the reader to recollect the prior texts when s/he encounters new texts. The comparative process and the horizon of expectation generates the aesthetic evaluative action in the immediate process which may vary according to the texts and the reading competence of the reader. (Boonkhachorn: 1992)

Traditional Thai literary convention also emphasizes the mimesis of the authorities or the imitation of the master pattern. The "paying respect to the teacher" tradition or "wai khru" is active not only in the literary field but also in other domains of cultural activities, such as music, painting, sculpture, etc. As for literary convention, this type of mimesis can be seen in the fixed structure of literary texts. These "fixed" or constant styles of narrating can be classified into two categories: general literary composition and the literary conventions for specific genre. The literary convention of mimesis offers two types of literary activity. First, the follower paradoxically copies the master as well as competes with him. In this way, the innovation is similar to restoration in the sense that the later poet chooses to follow only the best and improves the weak points for the better.

This paradigm of traditional Thai poetics dominates the literary world. It can be said that the perceptions of literature which are transmitted in the classroom are influenced by this paradigm.

\section{Part 2: The Hegemony: Literature as National History and Identity}

Somdet Krom Phraya Damrong Rajanuphap or Prince Damrong (18621943) played the most important role in Thai literary circle when he was the head of Wachirayan Library (at present, the National Library). He can be called the founding father of Thai historiography. The great achievement of Prince Damrong lies in his attempt to create a set of systems for Thai literary history. (Nagavajara, 1985) Most of the textbooks about the history of Thai literature published nowadays can be said to follow the pattern set by Prince Damrong. During the time when Prince Damrong was the head of the National Library, manuscripts were classified, edited and printed as books with brief introductions on each 
manuscript's history and its author. Prince Damrong himself was interested not only in literature but also history and archeology. $\mathrm{He}$ concentrated on editing Thai manuscripts and initiating the foundation of a historical approach to literature in the light of history and archeology. His historical approach to literature, together with biographical and generic approaches, emphasized the historical background of literary works and authors. He wrote studies on many important genres such as drama, the Sepha (a Verse Narrative), the Kap He Rua (The Boat Song) and Sakkrawa (Verse Repartee).

Prince Damrong in the History of the Royal Library explains the process of collecting and editing. Firstly, the staff had to act as collectors of the manuscripts. Secondly, they had to fulfil the function of editors, and thirdly, the personel also engaged themselves in the dissemination and promotion of the Thai literary heritage. In the Preface to Sepha Khun Chang Khun Phaen (The Story of Khun Chang Khun Phaen), Prince Damrong states that the process of editing various manuscripts was very complicated and difficult due to the variations of the different versions. $\mathrm{He}$ solved these problems by cutting out the obscene parts, by polishing up the vocabulary and style and by editing for the sake of coherence.

From this introduction it is interesting to note that the printed literary works circulated until the present time are products of the evaluative and editing processes of the period. Originally, Sepha Khun Chang Khun Phean was folk literature with all the elements of the folk literary tradition, such as sexual jokes, black humor and local color. The print version of Sepha Khun Chang Khun
Phaen is a sophisticated revised version of this folk masterpiece. It is, therefore, necessary to remind oneself of the differences between the manuscripts and the printed versions This process of "chamra" (meaning: to clean, to purify, to revise) or editing has been part of the literary tradition since the Ayutthaya period. In many manuscripts, at the end of the story, writers (or sometimes scribes) left the text "open", inviting later poets or readers to make revisions that they considered appropriate.

Prince Damrong's editing also emphasized the historical and biographical background of each literary text. He analysed,made comparisons of various versions of texts, and chose the one which he believed to be the most appropiate. Many texts, he concluded, had multiple authors over the course of their histories. Although Prince Damrong never wrote a complete history of Thai literature, it can be said that no history of Thai literature would have been possible without his pioneering efforts. As the authority of Thai literary historiography, he was the pioneer in this field. Obvionsly, his works have both strengths and weaknesses. His great achievement lies in the question of authorship, the writing of literary histories of some oral literary texts, and the development of literary genres within a historical framework.

However, there are many weak points in Prince Damrong's works which are worth considering. First, his standard of aesthetic and moral judgement was based on his social class, political values and aesthetic taste. This standard influenced his editing and the rewriting processes. Secondly, literary history from Prince Damrong's point of view, was dependent on political events, which he tended to use as the basis 
for dividing literary periods. In this way, literary history does not have a life of its own, as a cultural activity interrelated with others in the social process. "History" in this sense is the chronology of events which tend to center around the royal dynasty. Thirdly, his hypotheses about the historical period of some manuscripts have been proved by later schlolars to be wrong. However, because his is considered to be the authoritative voice, the majority of textbooks produced still take his assumptions to be fact.Prince Damrong's contribution to Thai literary studies helped later scholars such as, Pleung Na Nakhon to draw up a framework for the history of Thai literature based on his hypotheses of the time and period of each literary work. Because of the lack of textbooks on Thai literary history, Pleung $\mathrm{Na}$ Nakhon's Prawat Wannakhadi Thai Samrap Naksuksa (History of Thai Literature for Students), written in 1937 , is still the most popular in this field inspite of the fact that many of its classifications of literary works in historical periods, have been challenged by scholars. It is ironic that later scholars and students in this field have tended to follow Prince Damrong's work without further study or discussion. In the later period, when New Criticism entered the arena of Thai literary studies, this historical and traditional text-edit approach was largely ignored. Unfortunately, during these past three decades, there have been scholars who continue his task and challenge some of Prince Damrong's hypotheses, i.e. Sumalee Keeyakun, Niyada Laosunthorn.

During the past two decades a work by Niyada Laosunthorn, Literary Consideration (1992), is of interest in the way that it challenges established conclusions on literary history. The work, a compilation of her academic articles which survey the National library's literary manuscripts (situated in the Manuscript and Inscription service department); concentrates on, the history of Thai literature, the editing of manuscripts and the tracing of the real date of the writing of a text. It bravely challenges old conclusions. For example, in "Yuan Phai Klong Dan: New Proposal", she asserts that Lilit Yuan Phai was written during the reign of Phrabaromrajathirat III (1488-1491, the eldest son of Phrabaromtrailokanat). In "Phali Son Nong, Thotsarot Son Phra Ram and Ratchasawat : Who is the real author?", she proposes that King Barommakot wrote these three masterpieces and not King Narai, as concluded by the Literary association committee, headed by Prince Damrong.

In "Khlong Lokkanit: Study on its Sources" (1994), Niyada attempts to seek the sources of Klong Lokanit, written by Somdet Krom Phraya Dechadison, by the examination of its manuscript and its Pali and Sanskrit scriptures. It is not hard to say that Niyada has had a significant role in the survey of ancient literature, challenging long-established conclusions and producing new knowledge for literary studies.

There are few people who have attempted to conduct literary research by adopting historical approaches and concentrating on the editing of manuscripts. A portion of those who have are students at the Thai inscription section of Silpakorn University. For the most part the improvement of manuscripts has been the task of foreign scholars, such as Dr.Giles Delouche of the University of Paris (I.N.A.L.C.O). An expert in Tai, he deems the editing of manuscripts as crucial, proposing that scholars should explain the characteristics 
of each manuscript, compare them and thoroughly analyse each of them. These processes must be carefully observed so that scholars arrange literary texts accurately and present information from all the manuscripts available and not just from one version. Delouche considers the editing of manuscripts to be the most important process for literary studies to progress and be effective. Literary critics only waste their time if they trust poorly edited literary works. In order to work more effectively, Delouche suggests that literary scholars work together to edit manuscripts and to gather together every available version of a manuscript from everywhere in Thailand (National library, temples, personal collections). Then they should micro-film them and store this record in the Nartional library. In his consideration of further projects, he maintains that research be conducted on the Thai language, vocabulary, orthography and grammar, so that ancient Thai may be understood (Giles Delouche: 1985).

The trend in literary historiography and the editing of unpublished manuscripts has declined in the last two decades.

\section{Part 3: The West Wind: The Paradigm of the New Criticism}

The New Criticism first emerged in Thailand in the form of a series of articles written by H.H.Prince Narathipphongpraphan and printed in Prachachat after 1932. These articles were later collected and reprinted in a book titled, Witthaya Wannakam or Literary Knowledge. In his work, the prince stated that he had integrated the concepts of literary criticism from Arnold Bennett's Theory in Literary Taste by Aber Crombie, with those from I.A. Richards's
Principles of Literary Criticism. In his opinion, the guidelines for criticism have two steps. These are, firstly, to analyze the sounds of words and style which convey the deep meaning, and secondly, to proceed from sound to senses, images, and emotions. I.A.Richards'four kinds of meanings (sense, feeling, tone, and intention) were applied along with close reading practices to excerpts from Thai classical literature. Prince Narathipphongpraphan was the pioneer who introduced and applied the New Criticism to Thai literary study. Later on the New Criticism was explained in detail in the well-known textbook by Dr.Wit Siwasariyanon (first published in 1943): Wannakhadi lae Wannkhadiwijan (Literature and Literary Criticism). However, the New Criticism was not greatly influencial on Thai literary studies until the thesis "Kan Nam Wannakhadi Wijan Phaen Mai Ma Chay Kap Wannakhadi Thai" (The Application of the New Criticism to Thai Literature) by Chonthira Sattayawatthana in 1970. This Thesis presents a selection of major Western approaches which include the psychological approach of Sigmund Freud, the archetypal approach of Carl Gustav Jung and the aesthetic approach, especially the close reading technique of I.A.Richards. As for the aesthetic approach, the close reading presented in the thesis emphasizes the four kinds of meaning together with symbolism, paradox, and ambiguity. Excerpts from traditional and modern Thai literature are analyzed by using practical criticism as a paradigm of study.

This thesis established a precedent for succeeding graduate theses and has had a major influence on the teaching of Thai literature in higher education. The close reading technique seems to have been the 
most successful aspect of this thesis, which has influenced the study of Thai literature in many ways. Firstly, the application of the New Criticism to Thai literature revitalised the literary world, which at the time was stagnating in a technique of paraphrasing and the memorising of archaic vocabulary. Secondly, the aesthetic approach of close reading was compatible with traditional Thai literary studies, which emphasized aesthetic evaluation over interpretation. This "objective" or "scientific" approach seemed to upgrade with linguistic explanations the subjective mode of literary study. Thirdly for graduate study, the trend in literary research has been guided by the close reading approach (or the "micro" approach) limiting research to a single piece of literature and tending to ignore context, especially social context. It can be said that the objective of close reading is "aesthetic appreciation" instead of the many other modes of interpretation.

Another consequence of the institutionalization of the New Criticism is the focus on artistic creativity and original authorship. The most obvious evidence of this are the numerous literary awards which nowadays are major events in the Thai literary world. The intentional and the affective fallacies still play their important roles on the literary stage. With the institutional and pedagogical practices of the New Criticism still active, how can a paradigm shift occur in order to break out from the institutional self-closure and the closed evaluative criticism that limit the study of the wider social process within which texts are written and read?

\section{Part 4: The Anti-Hegemony: The Local Voice}

In these last two decades, the progress of folklore and local literary studies in many institutions all over the country is the promising sign. Studies in local literature have obviously been developed in quantitative terms. Many educational institutions have founded their own cultural centres, for examples those in, Chieng Mai, Mahasarakham and Songkhla. They also offer courses at the postgraduate level. These have led to a great number of theses and research papers dealing with the transliterations of old manuscripts, which in turn comprise the major database for studies in regional literature. In every region of Thailand, these centres for local cultural studies together with each institution's department of Thai language and literature play the important roles of, collecting, conserving and transliterating unpublished local manuscripts. Over the past three decades the study of local literature has become one of the major trends of Thai literary studies. Educational bodies which help champion such studies include the Thai Studies Section at Srinakharinwirot University-Songkhla, the Lanna Studies Section at Chieng Mai University and the Northeastern (I-san) Studies Section at Srinakharinwirot-Mahasarakham. Apart from these, research papers on manuscript transliteration can also be found at the Thai Inscription Section, the Department of Eastern Languages at Silpakorn University. The approaches and methodologies used in such theses and research papers include; those which 
attempt to depict the whole picture of regional literary studies; those which select to study the literature of a certain group of people; those which study regional literature in a comparative manner; and those which conduct studies on a definite topic or story.

Information concerning regional literature can be gathered from literal sources, such as "Koi"or "But" and palm-leaf manuscripts, or from interviews. It can be said that cultural centers in each region have played a significant role in gathering information before it is forever lost. Another point worth mentioning here is that not only information from each region from Thailand, but that from the Tai region in the South of China, has also been accumulated, resulting in the widening of the scope of literary studies in comparative manners.

Many MA. theses by graduate students of these universities are the products of editing these local treasures, i.e. "The Analysis of Tai Lu Langka Sip Hua (Tai Lu's Ramayana)" by Charoen Malaroj (1986) and the Comparative Studies of Nang Phom Hom in Lanna, Northestern, and Tai $\mathrm{Lu}$ versions" by Kaysorn Sawangwong (1988). Even though the theses have been conducted on a small and inclusive scale, they constitute an interesting trend in that they help to increase the amount of information about regional literature and extend knowledge of it to an international level. Moreover, these works in turn serve to preserve unpublished manuscripts and benefit studies on the Tai tribe (which to fully understand requires the application of other areas of studies).

In addition to research in the form of theses, there also exists an attempt by
Anatole Roger Peltier, a foreign researcher, to transliterate Tai $\mathrm{Lu}$ and Tai Kheun literature. Peltier is an expert on Lanna's art and culture, as can be seen from his transliteration of Chao Boonlong (The Golden Peacock), an ancient Lanna sermon (1992), and from his comparative study of the literary manuscripts, Tai Lu and Tai Kheun (from Chiengtung in Northern Myanmar).Both works were transliterated into Thai and later translated into French and English. By analysing and comparing versions of manuscripts, Peltier also transliterated Sukwanna Wua Luang, (the Golden Ox), a Tai-Kheun's local Buddhist Jataka from Chientung (1993), into Thai and later translated it into English and French. His research indicates an interesting trend in literary studies which should be encouraged, as it represents an attempt to preserve manuscripts before they vanish completely, as well as to make regional literature known to the nation.

Another foreigner who has played a prominent role in conducting research on Lanna regional literature is Harald Hundius from Kiel University, Germany. Not only does he take interest in transliteration research, but he has also studied the relationship between Lanna literature and society. $\mathrm{He}$ asserts that Buddhism has become a moral code which determines the mentality of its social members. Literature itself reflects the moral values which have been generated by Buddhism. Hundius remarks are also interesting because he believes that more important than the research itself is the fact that local monks and villager should be encouraged to appreciate and preserve their own cultural heritage, which they can make use of when studying their own intellectual heritage. It is his belief that should 
Thailand wish to preserve its uniqueness, this heritage itself will be of immense use later. (Harald Hundius: 1995)

The use of other areas of knowledge and other disciplines to study regional literature is another noteworthy trend. This leads us to better understanding in historical, social, and cultural manners. The Art\&Culture Pubishing House, led by Sujit Wongthet, organised an academic seminar on Mahakap Khong Usakhanay Thaw Hung Thaw Cheung Wiraburut Song Fang Khong ( The Epic of Southeast Asia: Thaw Hung Thaw Cheung Heroes of The Khong River), and collected a great deal of research work concerning this epic, conducted by academics from the past to the present, such as Jit Phumisak, Thida Saraya (a historian), Srisak Walliphodom (an archeologist), Prakong Nimmannhemin (a literary scholar), Maha Sila Wirawong and Duangduen Boonyawong, two academics from Laos. The study of a specific literary work from different perspectives, by scholars from different disciplines was an interesting exercise, even though the editor's conclusion could be contested on certain points. Such an academic seminar is able to generate knowledge which should be pursued further.

Further on the subject of regional literature, the thesis "MahaKap Thaw $\mathrm{Ba}$ Cheung: An Analytical Study" by Prakong Nimmanheminda (1987) represents an attempt to study this epic from the National Library's manuscript, (which Maha Sila Wirawong has transliterated). In this work Prakong conducted her study by comparing this manuscript with other versions of the epic. She then analysed the unity of it by judging its content and language, and provided an evaluation of it in terms of its artistic literary content.This thesis inspired the aforementioned seminar and proves that a thesis written in an educational institution can engender academic debate on a large scale, and make a contribution to new knowledge.

Comparative Studies in regional literature, whether the same work in the same period or different regions is comparatively studied, or whether local literary work is studied on the same lines as that of the royal court benefits the creation of a complete picture of Thai literary history. Theses in this line of study include "Shared Characteristics Between Phra Malay Phun Ban lae Phra Malay Kham Luang" by Wattana Na Nakhon (1982), (a thesis of the Program in Comparative Literature at Faculty of Arts, Chulalongkorn University); and also the thesis "Lanna's Versions of Ramayana: A Comparative Study" by Phichit Akkanit (1984). To date, however, a textbook or research is yet to be written on the complete picture of Thai literary history.

If we take a look at the research on regional literature in terms of regions, the studies in the North, the South and the Northeastern regions have greatly advanced. In each of the regions, local literary scholars can be referred to and the amount of research work is on the rise. Surprisingly, the Central region is the one in which the least amount of research work into regional literature has been conducted. The majority of the research work concentrates on oral literature, rather than on manuscripts. Many cultural centres in the Central region do not possess a satisfactory amount of research work dealing with the preservation, dissemination and survey of the region's literature. Perhaps the most outstanding Central cultural centre is the Petchaburi 
Teaching College, at which Lom Pengkaew holds a regular academic post.

The comparative perspective may guide this trend to the construction of the "real" Thai literary history. The distinguished scholars in this trend are, for examples, Sutthiwong Phongphaiboon, Thawat Poonnothok, Prakong Nimmanhaeminda, Udom Rungruengsri, Anatole-Roger Peltier and Harald Hundius.

\section{Part 5: The Outsiders: The Extrinsic and the Interdisciplinary Paradigms}

Rene Wellek \& Austin Warren in Theory of Literature divided the approaches to literary study into two types: the intrinsic and the extrinsic approaches. The extrinsic approach cover "other" disciplines, i.e. society, psychology, ideas. In Thai literary studies' domain, the contributions of the "outside" scholars are extremely challenging and productive. The best example is the debate about literature in the Early Rattanakosin period by Nithi Ieosriwong and the "inside" scholar, Duangmon Jitjamnong in her Ph.D. Thesis titled "Khunkha lae Laksana Den Khong Wannakhadi Samai Rattanakosin Ton Ton".

Nithi Ieosriwong, a distinguished historian, in Watthanatham Kradumphi cultures engendered the lively higher class culture of the Ayutthaya period. Kap Wannakam Ton Rattanakosin (Bourgeois Culture and Literature of the Early Rattanakosin Period) concludes that the literature of the Early Rattanakosin period was produced and consumed in the society when the Sakdina literary tradition of the late Ayuttaya period declined. The higher classes, a combination of the ruling class and the new bourgeoisie began to acknowledge the popular literary tradition. The combination of these two literary cultures engendered the lively high class culture of the Early Bangkok period.

The extrinsic paradigms generate in the literary world in these past three decades are, for examples, those of sociology, political sciences, history and Marxism.

\section{Epilogue and Trends for the Future}

In these past three decades, some interesting trends can be observed.

Firstly, the expansion of the literary texts as objects of study which covers not only the royal and religious texts, but also the oral and folk literary texts including the media creates new horizon for Thai literary studies. The emergence of local literary study is promising and flourishing in these last two decades.

Secondly, the New Criticism's paradigm is still very much present in academic institutions which tends to generate a historical and aesthetic-oriented perspective and lead to the "micro" study of literature.

Thirdly, the lack of new paradigms in literary discourse is one factor that causes the stagnance of Thai literary studies. The "extrinsic" scholars have made a much needed contribution of controversy and debate to literary circles, i.e. Nithi Ieosriwong and Sombat Janthornwong.

Under this circumstance, how can we move to the future?

\section{Thai Literary Studies in the Ivory Tower?}

The situation of literary studies in universities is not fundamentally different from the situation of the other disciplines, 
that is to say it has become too specialised. The problem remains of how to reconcile the "academic" literary studies with life in general and the culture of the world outside of the universities because the university is not the whole world.

\section{References}

Bassnett, Susan. 1993. Comparative Literature. A Critical Introduction. Cambridge: Blackwell Publishers.

Boonkhachorn, Trisilpa. 1992. Intertextuality in Thai Literary and Social Contexts: A Study of Contemporary Poets. A Dissertation for the Degree of Doctor of Philosophy (Comparative Literature). The University of Michigan. 1987. Patthanakan Kansuksa lae Khonkhwa lae Wijai Wannakhadi Thai. Bangkok: Faculty of Arts, Chulalongkorn University.

Graff, Gerald \& Gibbons, Reginald, ed. 1985. Criticism in the University. Tri Quarterly Series on Criticism and Culture, No 1. Illinois: Northwestern University Press.

Hawthorn, Jeremy. 1994. A Glossary of Contemporary Literary Theory. Second Edition. New York: Edward Arnold. Hudak, Thomas John. The Indigenization of Pali Meters in Thai Poetry. Southeast Asia Series Number 87. Athens, Ohio: Ohio University Press.

Koelb, Clayton \& Noakes, Susan, (ed.). 1988. The Comparative Perspective on Literature: Approaches to Theory and Practice. Ithaca: Cornell University Press.

Kuhn, Thomas S. 1970. The Structure of Scientific Revolutions. Second Edition. London: University of Chicago Press.

Nagavajara, Chetana. 1985. "Literary Historiography and Social-Cultural Transformation: The Case of Thailand," in Journal of the Siam Society: 73.
Raksamani, Kusuma. 1989. Kan Wikro Wannakhadi Thai Tam Thritsadi Wannakhadi Sanskrit. Bangkok: Mumlanithi Khrongkan Tamra Sangkohmsat lae Manutsayasat. Sattayawatthana, Chonthira. 1970. Kan Nam Wannakhadi Wijan Phaen Mai Baep Tawantok Ma Chai Kap Wannakhadi Thai. M.A. Thesis. Department of Thai, Chulalongkorn University.

Wellek, Rene \& Warren, Austin. 1977. Theory Of Literature. New Revised Edition. New York and London: A Harvest Book. 